D.O.I.: $10.3895 /$ gi.v10i3.1707

\title{
PADRONIZAÇÃO DAS ATIVIDADES DE MANUTENÇÃO EM UMA UNIDADE DO COMANDO DA AERONÁUTICA
}

\section{MAINTENANCE ACTIVITIES STANDARDIZATION OF A AIRFORCE COMMAND UNIT}

\author{
Raphael Azevedo Rosa ${ }^{1}$; Marcelo Augusto Oliveira da Justa ${ }^{2}$ \\ ${ }^{1}$ Universidade Federal do Amazonas - UFAM -Manaus/AM - Brasil \\ orosa_2006@yahoo.com.br \\ ${ }^{2}$ Universidade Federal do Amazonas - UFAM - Manaus/AM - Brasil \\ marcelo.justa@bol.com.br
}

\begin{abstract}
Resumo
O desenvolvimento da aviação comercial adicionou novos desafios à manutenção, pois obrigou o desenvolvimento de métodos preventivos, já que o reparo durante o voo raramente é possivel. Portanto, é função da atividade de manutenção repor as condições ideais de utilização dos equipamentos de vôo. No caso dos equipamentos de apoio a aviação, faz-se necessário uma manutenção adequada e conhecimento técnico especializado para garantir o funcionamento contínuo destes, mesmo em pleno voo. Neste contexto, é objetivo desta pesquisa é apresentar uma rotina de diagnóstico e análise para solução de problemas de manutenção corretiva para equipamentos de radiocomunicação do sistema VHF-300, do Quarto Centro Integrado de Defesa Aérea e Controle de Tráfego Aéreo (CINDACTA IV). Realizou-se também uma revisão da literatura, focada na manutenção, padronização e consulta aos manuais técnicos dos equipamentos. Com o intuito de alcançar o objetivo, foram levantados os problemas mais correntes do sistema VHF-300, a fim de propor uma padronização das ações de manutenção. Por fim, o resultado é o desenvolvimento de fluxograma que guia os técnicos de manutenção para a rotina de diagnóstico e análise para solução de problemas, procedimento documentado que não existia antes.
\end{abstract}

Palavras-chave: manutenção; padronização; procedimentos.

\section{Introdução}

A partir das últimas décadas, com o aparecimento das linhas de produção, a manutenção deixou de ser uma simples atividade de reparo para se tornar um meio essencial ao alcance dos objetivos e metas da organização, pois a parada dos equipamentos tem um grande impacto no custo final do produto.

A evolução dos equipamentos e a diversidades dos ativos físicos, tornou a manutenção uma função igualmente complexa, levando ao desenvolvimento de novas técnicas, modernas ferramentas de gestão e abordagem inovadoras da organização e da estratégia de manutenção. 
Também o desenvolvimento da aviação comercial adicionou novos desafios à manutenção, porque obrigou ao desenvolvimento de métodos preventivos, já que o reparo durante o voo raramente é possível e, além do mais, despertou para o problema da segurança de pessoas e bens.

Segundo o Centro de Investigação e Prevenção de Acidentes Aeronáuticos (CENIPA), os acidentes da aviação civil estrangeira no Brasil e aviação nacional no mundo, possuem crescentes taxas. Em 2013, até a data de 31 de julho, já ocorreram 103 casos, conforme Figura 1.

Figura 1 - Acidentes da aviação civil estrangeira no Brasil e aviação nacional no mundo

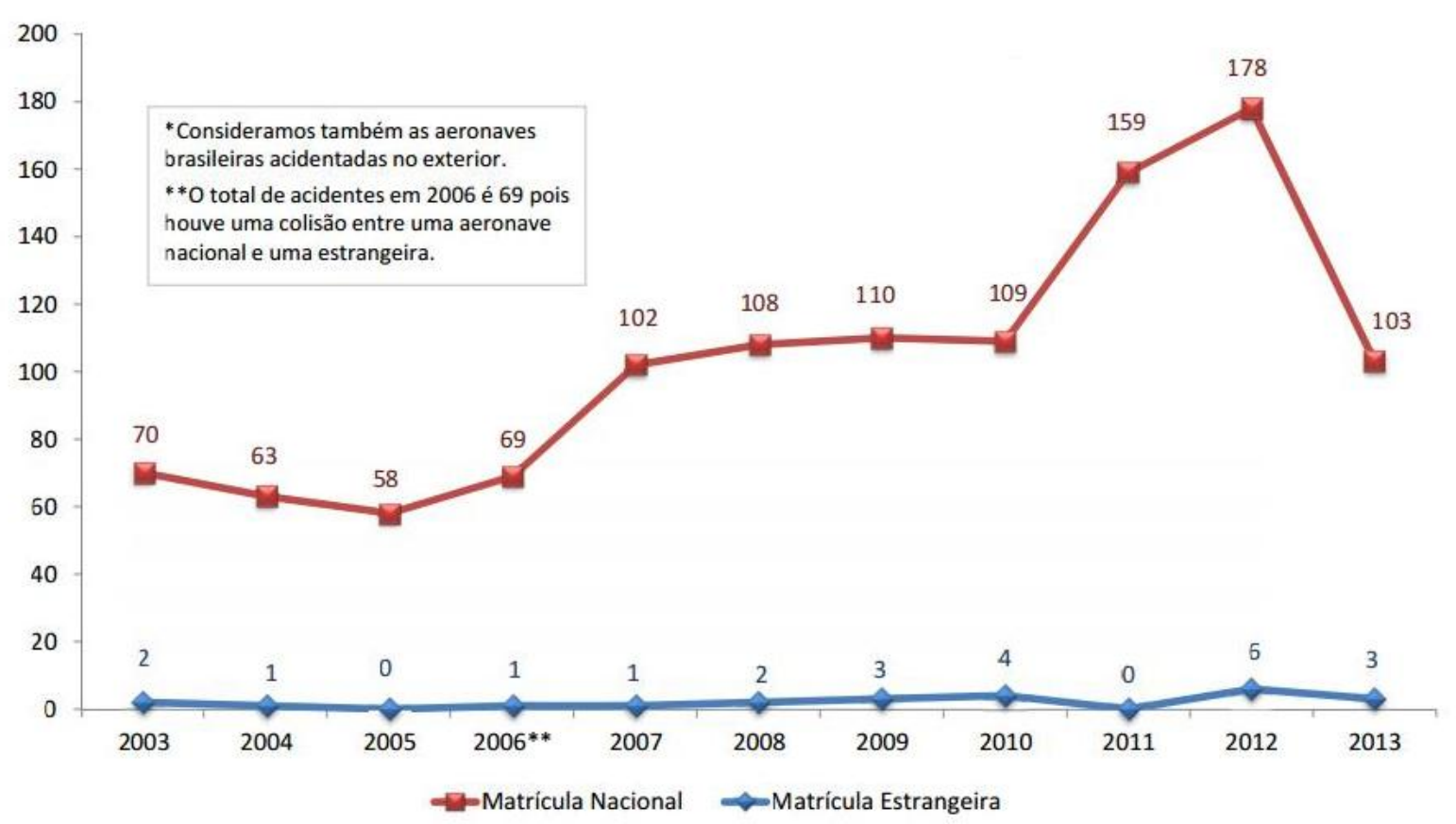

Fonte: CENIPA (2013)

Segundo Nicholas Payne (2006), os erros de manutenção estão presentes em aproximadamente $12 \%$ dos maiores acidentes aeronáuticos no mundo. Neste cenário, vale lembrar que todos os equipamentos e sistemas mecânicos, elétricos, eletrônicos, estão sujeito à degradação das suas condições normais de operacionalidade e confiabilidade com o decorrer do tempo. É função da atividade de manutenção em repor essas condições de utilização.

Neste contexto, a estrutura de planejamento e controle da manutenção tem um papel importante, fazendo com que os técnicos trabalhem de forma planejada, para que os recursos sejam aplicados de forma correta e no momento adequado, garantindo assim a disponibilidade dos equipamentos e uma maior segurança nos voos.

Diante deste cenário que enfatiza a importância das atividades de manutenção para a segurança aérea, realizou-se um estudo de caso em uma unidade do Comando da Aeronáutica no CINDACTA IV, focada na seção de Radiocomunicação. É nesta unidade que é acontece o controle e gerenciamento do espaço aéreo de aproximadamente $60 \%$ do território nacional. Portanto, tem 
como missão executar as atividades relacionadas com a vigilância e o controle da circulação aérea geral.

Figura 2 - Fatores contribuintes nos acidentes da aviação civil, entre 2003 a 2012

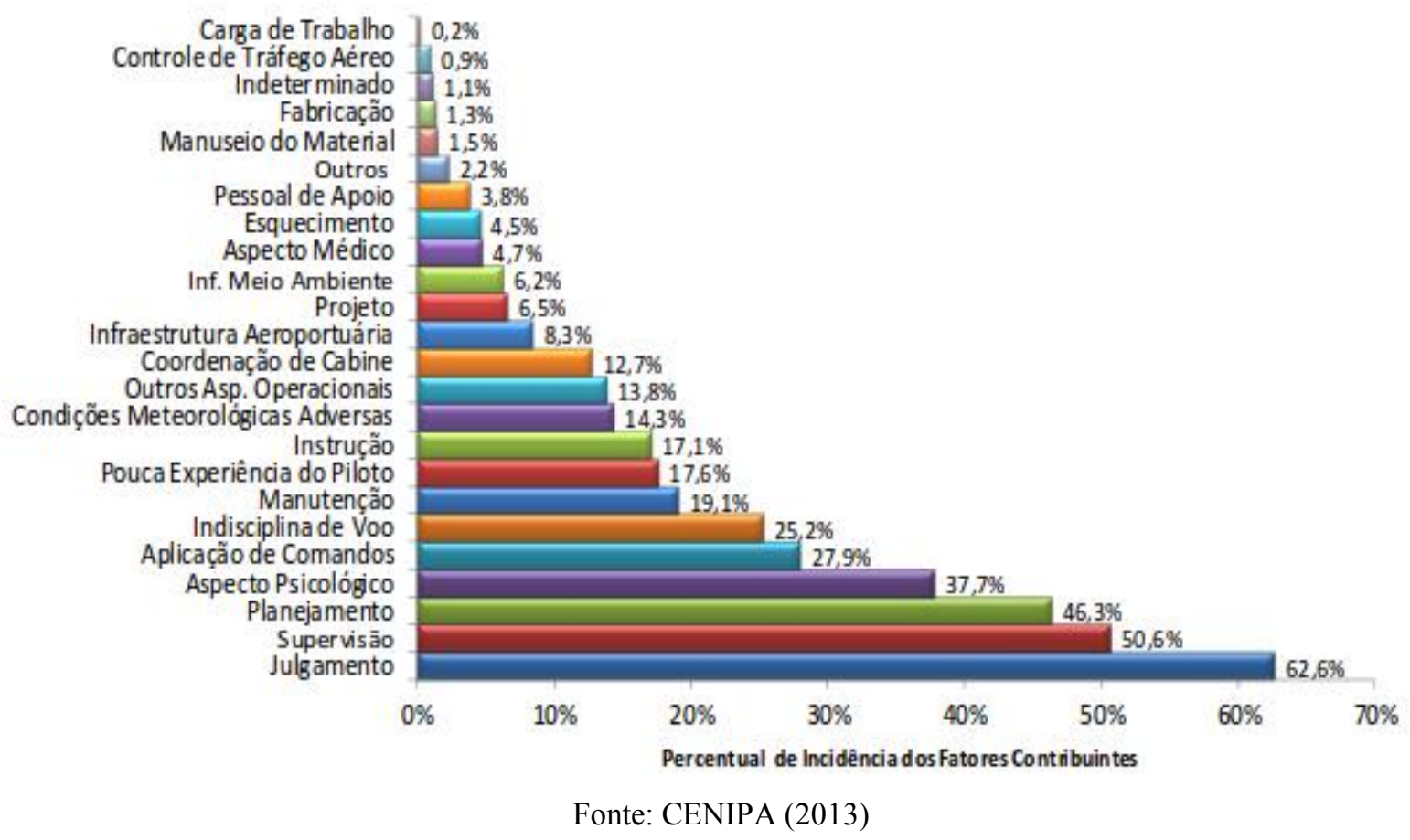

A Figura 2 ratifica a preocupação com a manutenção no cenário da aviação brasileira, No período de 2003 a 2012, percebe-se que a manutenção foi o fator contribuinte presente em 19,1\% dos acidentes aeronáuticos (CENIPA, 2013).

Neste contexto, destaca-se a falta de uma padronização das atividades de manutenção corretiva nos equipamentos de radiocomunicação. Estes equipamentos são fundamentais para o sistema de controle do espaço aéreo brasileiro, pois executa a comunicação do controlador aérea e o piloto da aeronave.

Devido a essa fundamental atividade, o objetivo do trabalho é desenvolver uma rotina de diagnóstico e análise de solução de problemas para auxílio na manutenção corretiva, bem como uma rotina de manutenção preventiva. Essa padronização proposta irá contribuir para facilitar o trabalho dos militares da seção de radiocomunicação, uma vez que a rotina será criada por meio de um fluxograma visual.

A pesquisa irá contribuir para a segurança na comunicação durante os voos comerciais e militares, pois as aeronaves necessitam de equipamentos que funcionem em perfeito estado em relação à comunicação entre controlador de voo e piloto em suas rotas aéreas. $\mathrm{O}$ intuito de padronizar as manutenções é de imprescindível relevância, pois se obtém uma alta qualidade e confiabilidade do serviço realizado.

Outro fator importante e a alta rotatividade de militares que ocasiona a incapacitação técnica 
de um determinado equipamento. Para tal, um planejamento padronizado das manutenções será desenvolvido, a fim de ser utilizado de forma compatível no CINDACTA IV.

\section{Metodologia}

Os procedimentos metodológicos empregados na pesquisa, de acordo com as definições de Vergara (2004) e Rudio (2007), quanto aos fins, é classificada como descritiva, pois descreve os fatos e características presentes em uma determinada população.

Quanto aos meios, a pesquisa é definida como bibliográfica, pois aborda os principais tipos de manutenção, bem como os pontos fundamentais da confiabilidade e padronização. E também é classificado como estudo de caso, porque abordou a situação real de uma empresa.

E enfim, a pesquisa quanto ao processo é qualitativa, pois o objetivo esta na compreensão dos fatos sem a utilização de dados estatísticos.

A pesquisa iniciou-se consultando o banco de dados de equipamentos defeituoso, da seção de radiocomunicação, que necessitavam de manutenção. Foi observado um histórico anterior de falhas e problemas que poderiam ser eliminados com um mínimo de atenção para essas ocorrências. Logo, a precisão de uma padronização da manutenção, tanto preventivo quanto corretivo, será considerada, com o intuito de reduzir ao máximo as panes mais conhecidas pelos técnicos que possuem experiência nesses equipamentos.

Para desenvolver a padronização das manutenções aplicou-se uma das ferramentas da qualidade, o fluxograma. A ferramenta utilizada neste trabalho representa um funcionamento de procedimentos de manutenção, que permiti um entendimento rápido para ações corretivas.

Por fim, foi realizada uma pesquisa da percepção qualitativa com os 10 militares que trabalham na seção de radiocomunicação, no qual constava o grau de satisfação dos procedimentos de manutenção de antes e depois da implantação dos métodos padronizados da manutenção. Além disso, a pesquisa abordou as opiniões, com relação às atividades de manutenção padronizada, se elas possuíam algum benefício. E também foi perguntado como os técnicos executavam o serviço sem a padronização.

\section{Fundamentos teóricos}

\subsection{Manutenção}

Segundo Pinto e Xavier (2001), a palavra manutenção é derivada da palavra latim mantenus tenere (manter aquilo que se tem). A manutenção é uma combinação de ações de gestão, aplicadas a equipamentos e bens para aperfeiçoar o tempo de vida. Neste contexto, a definição de manutenção está relacionada com os diversos cuidados técnicos indispensáveis para uma melhor confiabilidade 
dos equipamentos (FERREIRA, 1999).

Pinto e Xavier (2001) destacam que os principais tipos de manutenção são: Manutenção Preventiva, Manutenção Corretiva e Manutenção Preditiva. Nesta pesquisa foram desenvolvidos os planos de manutenção corretiva e preventiva do equipamento delineado, devido à aplicação e os modos como são realizadas essas manutenções.

Viana (2002) considerada a manutenção preventiva com o a mais importante dentre os tipos de manutenção, pois envolve atividades de planejamento prévio e a execução de tarefas periódicas, realizadas de forma sistemáticas, tais como: inspeções gerais, substituição de componentes, lubrificação e limpeza. Estas intervenções são definidas e executadas por especificação do fabricante e ou com base em dados que são proporcionais à deterioração do equipamento.

Para Kardec e Nascif (2001) a manutenção corretiva somente é efetuada após a ocorrência de uma falha ou quebra, e é destinada a colocar um item em condições de executar uma função requerida. E Eduardo (2003), menciona que a manutenção corretiva é a que acarreta os maiores custos associados à perda de produção, uma vez que as paradas são inesperadas e não há a possibilidade de efetuar um planejamento eficiente.

No Comando da Aeronáutica, de acordo com a IMA 19-87 (1998), as manutenções são divididas em três níveis: Orgânico, Base e Parque. O CINDACTA IV realiza apenas as manutenções de nível orgânico e base.

A manutenção de nível orgânico são ações de manutenção executadas no equipamento pelo utilizador, operador ou por pessoas especialmente treinadas do órgão utilizador. Compreendem basicamente os serviços de limpeza e conservação do equipamento instalado, troca de lâmpadas, fusíveis e subconjuntos.

O outro tipo de nível de manutenção realizado no CINDACTA IV é a de base, ela é executada pelo órgão de apoio específico. Compreende reparos que requeiram oficinas fixas ou equipamento estacionário, substituição de conjuntos, fabricação de peças simples e o cumprimento de ordens técnicas. Compreendem basicamente os serviços de verificação de níveis, reajustes, trocas de lubrificantes, de cartões e de componentes especiais.

Lafraia (2001) destaca que com o surgimento da indústria aeronáutica, após a Primeira Guerra Mundial, Henley e Kumamoto desenvolveram os primeiros estudos de analise de confiabilidade. Na aviação, devido o risco da atividade, a gestão da manutenção e confiabilidade devem ser eficiente e eficaz, uma vez que acidentes podem acarretar em fatalidades.

Segundo Bergamo (1997) a confiabilidade se define pela capacidade de utilização de um equipamento realizar suas funções sem ocorrência de problemas, durante um determinado período de tempo. Outra definição, afirma que a confiabilidade é uma ferramenta que permite a elaboração 
de estratégias de manutenção, pois visa garantir o bom funcionamento do produto, em decorrência do seu tempo de uso e dos fatores que podem influenciar seu desempenho (FIRMINO et al, 2004).

\subsection{Padronização}

Para melhorar o gerenciamento das manutenções e aumentar a confiabilidade dos equipamentos, pode-se desenvolver a normalização técnica das manutenções. ABNT (2006) define normalização como processo que estabelece, em relação a problemas existentes ou potenciais, ações destinadas as atividades comuns e repetitiva para obtenção da otimização em um dado contexto.

Os objetivos principais da normalização são: Definir os requisitos necessários à obtenção da qualidade; proteger a população em aspectos relacionados à saúde e segurança; proporciona meios mais eficientes para assegurar a absorção e transferência de conhecimentos para executar os serviços de manutenção e promove soluções para problemas repetitivos, aumentando a produtividade e reduzindo os desperdícios (ABNT, 2006).

Segundo Oliveira (1991) a normalização técnica baseia-se em um conjunto dos resultados da ciência, tecnologia e experiência prática. Ela tem como objetivo ter um consenso entre fabricante, técnico e o usuário. Com a utilização da normalização consegue-se acelerar as decisões, reduzir as variedades das operações da manutenção e obter soluções rápidas e seguras para problemas reincidentes. O CINDACTA IV deve desenvolver um sistema de normalização, pois é uma forma de registro de conhecimento, fato que pode ser perdido com a transferência do militar. Através da normalização obtém-se a padronização na execução dos serviços de manutenção, aumentando a qualidade, a confiabilidade e a segurança.

Oliveira (1991) menciona que existem diversos tipos de normas: ensaio, método de análise, terminologia, especificação, simbologia e padronização. Na manutenção os mais utilizados são: padronização e especificação. Uma padronização precisa ser desenvolvida quando há necessidade de estabelecer requisitos básicos e ações necessárias para a execução de um trabalho. Ela é importante para a execução de um mesmo trabalho realizada por diferentes pessoas e para treinamento de novos militares.

Campos (2004) destaca que a padronização de um processo consiste na elaboração de rotinas formalizadas para executar atividades de manutenção. Ou seja, a padronização é usada como ferramenta gerencial que possibilita a transmissão de informações e conhecimentos adquiridos.

Portanto, a padronização é essencial para que o trabalho da manutenção seja conduzido de forma eficiente é confiável. Conforme Curi Filho (1999), os benefícios da padronização da manutenção são: 
a) Aumento na capacidade de treinamento de novos profissionais num espaço de tempo mais curto, permitindo que os técnicos sejam capazes de executar tarefas complexas que antes eram feitas por técnicos mais experientes;

b) Permite acumular o domínio sobre a manutenção dos equipamentos da unidade, evitando que o conhecimento se perca com a transferência dos militares da seção;

c) Contribui para a melhoria do planejamento da manutenção, reduzindo os tempos para execução das tarefas, facilitando o planejamento logístico e a redução da indisponibilidade dos equipamentos;

d) Contribui para eliminação dos desperdícios com peças de reposição e matérias sem utilização e aumenta a produtividade da mão de obra;

e) Aumenta a confiabilidade das ações da manutenção, reduzindo as paradas por falhas reincidentes.

Para dar início à padronização é preciso ter um objetivo definido e o conhecimento de sua necessidade, com isso deve-se elaborar um fluxograma. De acordo com Campos (2004) é com o fluxograma que se dá inicio a padronização.

\subsection{Fluxograma}

Hoje em dia as empresas têm preocupações com a qualidade de produtos e serviços. Com isso, os conceitos e ferramentas da qualidade evoluíram e chegam ao ponto de serem considerados instrumentos básicos para o planejamento empresarial (COSTA NETO, 2007).

Juran e Gryna (1991) define qualidade como um conjunto de característica do produto que satisfaz a necessidade do cliente. Oakland (1994) afirma que a noção de qualidade depende fundamentalmente da percepção de cada um. O que tem qualidade para algumas pessoas pode não suprir as necessidades de outras, ou seja, o conceito de qualidade dependeria de cada indivíduo. Xenos (1998) menciona que a qualidade da manutenção está ligada a procedimentos de combate às falhas e suas causas, ao bom entrosamento da equipe, ao aumento da produtividade e à definição dos procedimentos da organização.

Segundo Garvin (1992) existem 7 ferramentas da qualidade mais utilizadas, entre elas o fluxograma. O fluxograma é uma representação gráfica de um determinado processo, caminho ou fluxo de trabalho efetuada com símbolos padronizados unidos por setas. Com o fluxograma é possível compreender de forma rápida e fácil as etapas de manutenção e o serviço que deve ser realizado. A existência de fluxogramas para cada um dos equipamentos é fundamental para a simplificação e racionalização do trabalho, permitindo a compreensão e a redução do tempo das manutenções. 


\section{Levantamento dos equipamentos}

O CINDACTA IV possui diversas áreas de atuação, como por exemplo, meteorológica e navegação, com inúmeros equipamentos. Portanto, este trabalho está focado aos materiais voltados à comunicação entre as estações solo e aeronaves, podendo, ser futuramente expandido para os outros sistemas. No Quadro 1 pode-se verificar um histórico de problemas correntes dos equipamentos de radio comunicação que somados correspondem a 78\% do índice de falhas.

Quadro 1 - Histórico de problemas correntes dos equipamentos de radiocomunicação

\begin{tabular}{|c|c|c|c}
\hline Item & Equipamento & Defeito & Módulo \\
\hline 1 & VHF-310 & Baixo alcance de propagação & Módulo amplificador de potência \\
\hline 2 & VHF-320 & Travamento de memória EEPROM & Fonte reguladora \\
\hline 3 & VHF-350 & Não comutação do transmissor & Relés de comutação \\
\hline 4 & VHF-310 & Desarma por baixa potência & Módulo amplificador \\
\hline 5 & VHF-320 & Sinal demodulador não sensibiliza Squelsh & Módulo demodulador de RF \\
\hline 6 & VHF-330 & Baixo alcance & Acoplador de antena \\
\hline
\end{tabular}

Fonte: Seção TTRD (2013)

Dessa forma, observa-se que os equipamentos do sistema VHF-300 são críticos no que tange a existência de problemas. Esses equipamentos que foram analisados para o planejamento das manutenções são de comunicação. Na área da Amazônia são utilizados os Very High Frequency (VHF) da serie 300

O VHF-300 é um sistema de radiocomunicação de apoio às aeronaves. A estação integrada consiste de dois transmissores VHF-310, dois receptores VHF-320 para demodulação de rádio frequência (RF), ou seja, transformar sinal modulado em áudio, e um comutador controle local VHF-350. Ou também, podem ser instalados com dois transceptores VHF-330, e uma unidade comutadora controle local VHF-350. Esses equipamentos são responsáveis pela emissão e recebimento do sinal de áudio entre as comunicações ar-terra.

O VHF-310 - Unidade transmissora de VHF é o equipamento responsável por processar o áudio de voz, convertê-lo em sinais de radio frequência $(\mathrm{RF})$ e de forma englobada ao raio de alcance determinado espalha com a potência selecionada esse tipo de sinal para o ar, de forma que a aeronave ao alcance receba este áudio convertido (TECNASA, 1993).

De acordo com a Tecnasa (1993), o VHF-320 - Unidade receptora de VHF é o equipamento que descentraliza todos os sinais de RF recebidos e seleciona, na frequência referenciada, e o converte para a forma de áudio na qualidade de voz da mesma maneira que esta foi transmitida para do ar para o solo.

O VHF-330 - Unidade transmissora e receptora de VHF é o equipamento integrado que possui as funções do VHF-310 e VHF-320 em um único módulo. O VHF-330 e VHF-310 são 
divididos em quatro etapas: Unidade controladora de áudio que é responsável por processar todo o sinal de áudio que trafega no transmissor, essa etapa contém a interface analógica com o microprocessador; Unidade controladora de radiofrequência (RF) que é responsável por gerar todos os sinais de RF usados no circuito de transmissão do equipamento, essa etapa é realizada pelo sintetizador; Unidade amplificadora responsável por transmitir o sinal RF amplificado com um máximo de potencia; e Unidade reguladora de voltagem responsável por suprir voltagem de entrada regulada da fonte AC e DC (TECNASA, 1993).

Segundo a Tecnasa (1993), o VHF-350 - Unidade comutadora de VHF é o equipamento responsável por comutar os conjuntos principais e reservas de transmissores e receptores ou de transceptores, e vice-versa, quando estes se encontram com algum problema detectado por ele.

\section{Manutenção atual no CINDACTA IV}

Os planos de manutenção são elaborados, quando existir, pelo Parque de Material de eletrônica da Aeronáutica do Rio de Janeiro, que é a organização central referente a equipamentos de proteção ao voo, através da Subdivisão de Planejamento. No âmbito do CINDACTA IV os planos de manutenção são enviados para a seção de planejamento e controle técnico que tem como finalidade coordenar as atribuições com as oficinas de reparo.

Com relação às manutenções preventivas, elas são elaboradas de acordo com as ordens técnicas do próprio equipamento, estão relacionadas de forma a precaver possíveis problemas no sistema, logo possuem uma periodicidade correlata com a necessidade técnica e documental. Esse tipo de manutenção é realizado por fichas preventivas mensais e semestrais para cada equipamento, de modo que gere um controle por parte da seção de planejamento técnico.

Para as manutenções corretivas, não existe nenhum plano, ocorrendo assim um problema, pois na maioria das vezes, apenas técnicos experientes conseguem identificar e executar a manutenção adequada.

Outro problema que ocorre é a falta de equipamentos para apoio a manutenção, tais como instrumentos de medição e componentes. E também, a falta de padronização dos locais destes equipamentos de apoio, o que impacta diretamente no tempo do serviço da manutenção.

Em fim, a maior dificuldade de hoje é em relação à logística, uma vez que os equipamentos de radiocomunicação estão instalados em diversas cidades e estados brasileiros. Este fato implica diretamente com a manutenção, pois não há aeronaves disponíveis para traçar toda rota e dar apoio para as manutenções preventivas mensais. Então, essas manutenções muitas vezes ficam a cargo dos técnicos locais, e por este fato é necessário um plano de manutenção padronizado.

Filho (2005) destaca que um sistema de manutenção informatizado permite a interação da manutenção com as demais áreas da empresa, tornando o gerenciamento de custos, materiais e 
pessoal mais ágil e seguro. O fator primordial da informatização da manutenção é o gerenciamento dos equipamentos e instalações, visando possibilitar a formação de um banco de dados histórico dos equipamentos, o planejamento e programação de recursos para a manutenção, orientar atividades e estabelecer o panorama das condições dos equipamentos.

No Comando da Aeronáutica utiliza-se para gerenciar todo o histórico da manutenção o software Sistema Integrado de Logística de Materiais e Suprimento (SILOMS). Esse programa contém as atividades envolvidas nos procedimentos técnicos, com possibilidade de lançamento dos acontecimentos e eventuais problemas e/ou restrições ocorridas durante a referida manutenção, bem como as horas trabalhadas para o técnico que realizou a tarefa, podendo assim controlar sua produtividade.

Este software, além de gerenciar a manutenção, controla a logística de materiais. Conforme os manuais técnicos da Tecnasa (1993), a manutenção corretiva deve ser descrita de acordo com a operação do equipamento e cada manutenção deve acompanhar substituições de cartas e componentes, quando necessário. De acordo com este procedimento, é importante possuir componentes extras no estoque do suprimento técnico para uma rápida solução de problemas.

Para sanar os problemas que possam ocorrer nos equipamentos estudados é possível que haja substituições de cartas e componentes de um ou mais itens do conjunto delineado. Dessa forma, é importante que exista um estoque seguro e suficiente para uma imediata substituição da peça avariada. Um plano de compras é adotado na Unidade, para que todos os sistemas possam funcionar sem problemas.

Esse plano de aquisição de itens é realizado pela Subdivisão de suprimento, leva em consideração a criticidade e a alta rotatividade de utilização do ano anterior e a quantidade de estoque atual. Estes dados são retirados através do SILOMS e repassados as oficinas para confirmação da compra do material. As peças de reposição que englobam o Sistema VHF-300 são listados no manual técnico do equipamento.

Para realizar as manutenções, alguns procedimentos podem requerer uso de instrumentação específica para ajuste e verificação em vários pontos do transmissor, receptor e transceptor. Esses procedimentos são: ajuste de nível de Squelsh, ajuste da voltagem do sintetizador, teste de sensibilidade, teste de intermodulação, ajuste de seletividade do receptor, ajuste da fonte reguladora de tensão, sequenciamento do nível de saída de áudio e controle de auto falante. Para executar as referidas atividades é preciso a utilização dos seguintes instrumentos: osciloscópio, multímetro analógico, analisador de áudio, divisor de potência, analisador de espectro, gerador de RF, fonte de alimentação e voltímetro.

Como o equipamento VHF-300 esta sendo utilizado há 20 anos, sua confiabilidade não é satisfatória. Portanto é necessário à realização de uma proposta de um plano de manutenção, 
principalmente corretivo que possuem a maior criticidade, para resolver a falta de gerência e coordenação e agilizar os procedimentos de manutenção interna.

\section{Proposta da padronização das manutenções}

Para se desenvolver a padronização da manutenção, foi organizado em um arquivo todo o histórico técnico e funcional do equipamento para auxiliar em uma eventual manutenção corretiva.

O plano de manutenção preventiva é aceitável e deve seguir o período como descrito nos manuais técnicos e acordado no Sistema de controle logístico do planejamento técnico. Então a elaboração estará relacionada à manutenção corretiva que envolverá questões práticas para análise de problemas dos equipamentos.

As manutenções foram organizadas conforme atividades a serem executadas bem como periodicidade, nível, carga horária de manutenção e peças a serem substituídas, conforme Quadro 2.

Quadro 2 - Plano de manutenção preventiva

\begin{tabular}{|c|c|c|c|c|}
\hline Equipamento & Nível & Periodicidade & Duração & Itens a serem inspecionados. \\
\hline VHF-300 & Orgânica & $1^{\text {a }}$ Mensal & 03:20 & Unidade controladora de áudio e Unidade Amplificadora \\
\hline VHF-300 & Orgânica & $2^{\mathrm{a}}$ Mensal & 03:20 & Unidade controladora de áudio e Unidade Amplificadora \\
\hline VHF-300 & Orgânica & $3^{\text {a }}$ Mensal & 03:20 & Unidade controladora de áudio e Unidade Amplificadora \\
\hline VHF-300 & Orgânica & $4^{\mathrm{a}}$ Mensal & 03:20 & Unidade controladora de áudio e Unidade Amplificadora \\
\hline VHF-300 & Orgânica & $5^{\mathrm{a}}$ Mensal & 03:20 & Unidade controladora de áudio e Unidade Amplificadora \\
\hline VHF-300 & Base & $\begin{array}{l}1^{\text {a }} \text { Semestral } \\
6^{\text {a }} \text { Mensal }\end{array}$ & 08:10 & $\begin{array}{l}\text { Unidade controladora de áudio e de RF, Unidade } \\
\text { Amplificadora e Unidade Reguladora de Tensão. }\end{array}$ \\
\hline VHF-300 & Orgânica & $7^{\mathrm{a}}$ Mensal & 03:20 & Unidade controladora de áudio e Unidade Amplificadora \\
\hline VHF-300 & Orgânica & $8^{\text {a }}$ Mensal & 03:20 & Unidade controladora de áudio e Unidade Amplificadora \\
\hline VHF-300 & Orgânica & $9^{\text {a }}$ Mensal & 03:20 & Unidade controladora de áudio e Unidade Amplificadora \\
\hline VHF-300 & Orgânica & $10^{\mathrm{a}}$ Mensal & 03:20 & Unidade controladora de áudio e Unidade Amplificadora \\
\hline VHF-300 & Orgânica & $11^{\mathrm{a}}$ Mensal & 03:20 & Unidade controladora de áudio e Unidade Amplificadora \\
\hline VHF-300 & Base & $\begin{array}{l}2^{\mathrm{a}} \text { Semestral } \\
12^{\mathrm{a}} \text { Mensal }\end{array}$ & 08:10 & $\begin{array}{l}\text { Unidade controladora de áudio e de RF, Unidade } \\
\text { Amplificadora e Unidade Reguladora de Tensão. }\end{array}$ \\
\hline
\end{tabular}

Fonte: Manual da Tecnasa (1993)

A elaboração do mapa de manutenção foi construída de acordo com o diagrama interno do equipamento utilizando o manual técnico dos equipamentos. Seu entendimento versa de uma especificação técnica em nível de fluxograma e blocos.

A padronização das manutenções abordará os problemas que já ocorreram nos 
equipamentos, observado no histórico de manutenção. A aplicação dessas ações de manutenção tem como base os problemas mais comuns para que se pudesse avaliar a sua eficácia na referida solução da pane.

Através do histórico de manutenção foram observados os problemas que já ocorreram nos equipamentos de radiocomunicação, elaborando assim, uma proposta de manutenção corretiva para os problemas mais contínuos sendo:

a) Baixo alcance: o problema aqui citado envolve mais o recebimento de sinais de RF, logo envolve parte de RX do transceptor VHF-330. Delineando o defeito, verifica-se que esta não é externa, concentra-se então no acoplador de antena, devido às cartas internas todas do transceptor, serem usadas para as ambas as funções, pois o equipamento tem a funcionalidade de transmissão e recepção. Assim, o problema é a interconexão com a antena ou o conector de RF do rádio, principalmente se forem usadas antenas isoladas de recepção e transmissão;

b) Baixo alcance de propagação: sabendo que alcance de envio está cabível somente ao transmissor e ao transceptor na fase TX. Com baixo alcance, seria medida a potência do rádio respectivo, para isolar o problema de potência refletida ou direta, pois se considera que o defeito está dentro do sistema;

c) Desarma por baixa potência: o desarme é ocorrido, se a potência nominal do transmissor ou do transceptor for menor que $15 \%$ da nominal reduzida $(25 \mathrm{~W})$, assim, com $21 \mathrm{~W}$ ( $25 \mathrm{~W}$ x 85\%). No entanto, uma das formas de isso acontecer é a alimentação repassada de valor diferenciado ao amplificador, que normalmente parte das falhas de $+15 \mathrm{~V}$. Este problema de alimentação do rádio ocasionada pelas falhas de 15 e $28 \mathrm{~V}$ pode ser devido a fusíveis, conexões ou cartões defeituosos;

d) Travamento de memória EEPROM: este problema pode ocorrer em todos os componentes do Sistema VHF-300, exceto no controle local. Porém a ocorrência mais reincidente é no receptor VHF-320. Essa maior ocorrência, é devido a um componente falho na carta demoduladora, responsável também por parte da tensão de alimentação do painel frontal;

e) Sinal demodulador não sensibiliza Squelsh: o defeito é de modulação de áudio recebido, assim, existe funcionamento básico de batimentos e controle de ganhos. Por squelsh, entende-se como o limiar de sinal recebido que poderá ser liberado, ou não, de acordo com a demodulação realizada pelo próprio receptor.

Não comutação do transmissor: a comutação é responsabilidade do controle local VHF-350 dentro do sistema. O controle local tem função especial no Sistema VHF-300, pois este possui um funcionamento na integração de equipamentos principais e reservas. A comutação relacionada 
envolve um conjunto de telecomunicadores que chaveiam a parte de áudio e de RF em sua totalidade.

Para resolver o problema em questão devem-se analisar os 3 mapas de manutenção do controle local, que são mostrados nas Figuras 3, 4 e 5, pois o problema envolve a função total do equipamento supracitado. Os organogramas são altamente funcionais para a resolução de quaisquer falhas que possam ocorrer no equipamento.

Figura 3 - Fluxograma para manutenção corretiva no VHF-350 (Fase de RF TX/ RX)
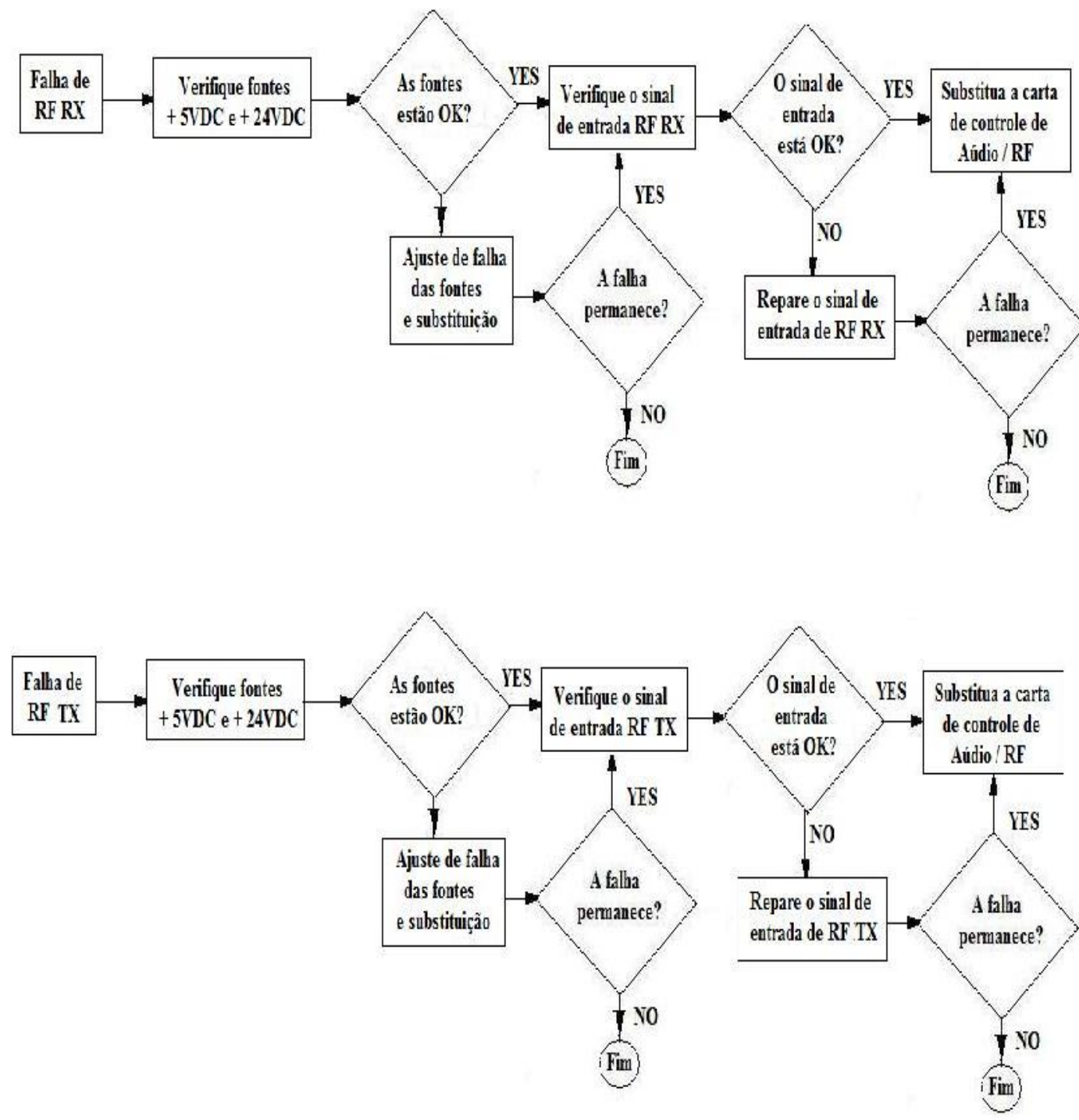

Fonte: Autoria própria (2013)

Este fluxograma é para diagnóstico de problemas no Controle Local relativo a falhas que possam ocorrer na Fase de RF TX e RX. Os procedimentos para analise da falha do TX e RX são idênticos. Inicia-se verificando as fontes +5 VDC e + 24 VDC com o multímetro, se estiverem boas deve-se verificar o sinal de entrada RF TX/RX com o auxílio do instrumento analisador de espectro. O sinal estando ruim utiliza-se o gerador de RF para reparar o sinal de entrada, permanecendo o problema, a falha sobe ser da carta de controle de áudio/RF que deve ser substituída. 
Figura 4 - Fluxograma para manutenção corretiva no VHF-350 (fase de alimentação)
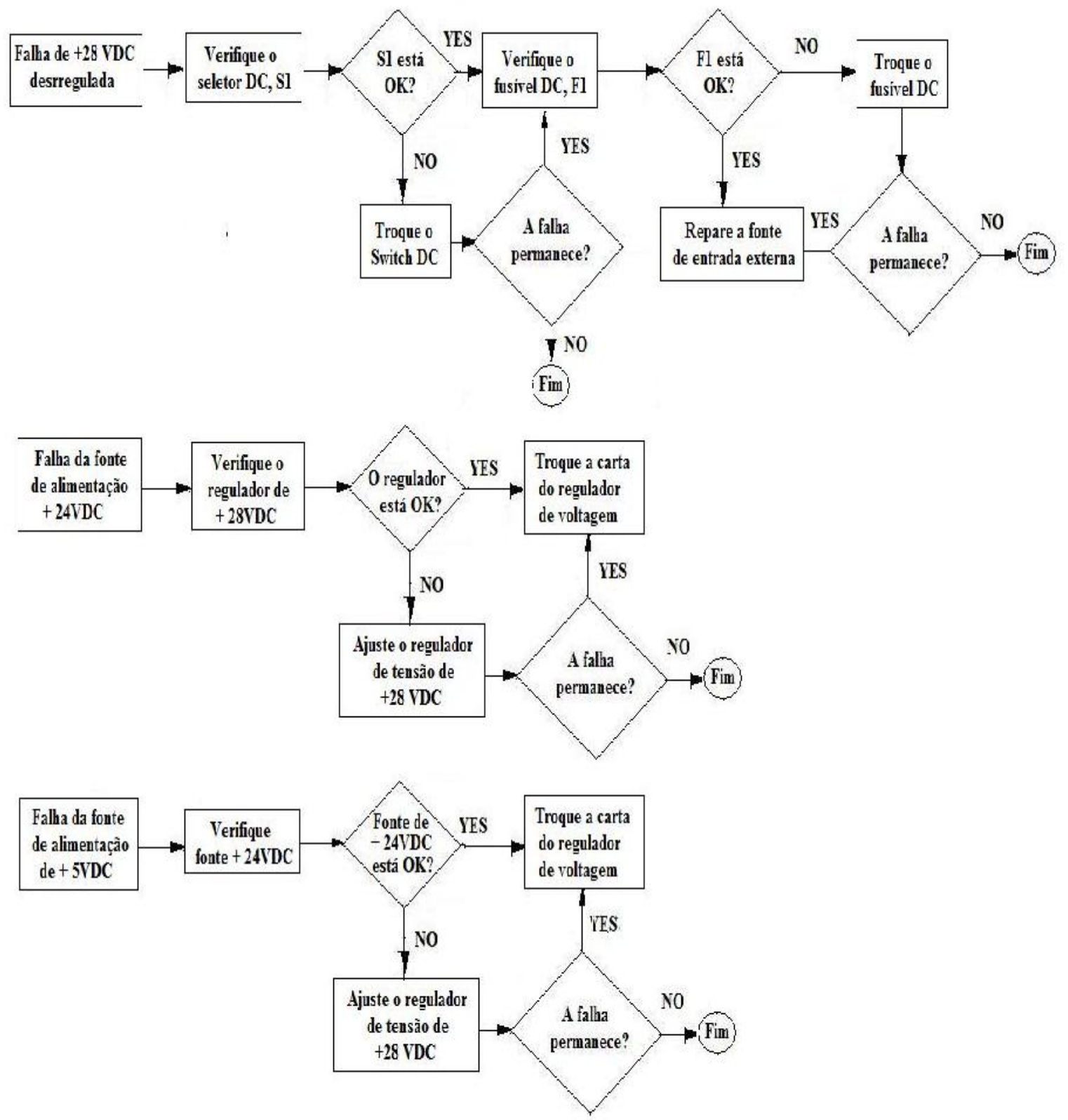

Fonte: Autoria própria (2013)

Este fluxograma é para diagnóstico de problemas no controle local relativo a falhas que possam ocorrer na fase de alimentação. Os procedimentos podem ser divididos em duas etapas alimentação interna e externa. Na interna pode ocorrer a falha na fonte de alimentação + 24 VDC e +5 VDC, inicia-se verificando através do multímetro a fonte +24 VDC ou regulador de +28 VDC, se a fonte ou regulador estiverem bons, deve-se trocar a carta do regulador de tensão. No caso de falha na alimentação externa, ou seja, falha de +28 VDC desregulada. O primeiro passo e verificar o seletor DC, S1 com o multímetro, se estiver em perfeito estado, com o multímetro, deveremos verificar o fusível DC, F1, achando o problema deveremos trocar este fusível.

Figura 5 - Fluxograma para manutenção corretiva no VHF-350 (fase de áudio e modulação) 

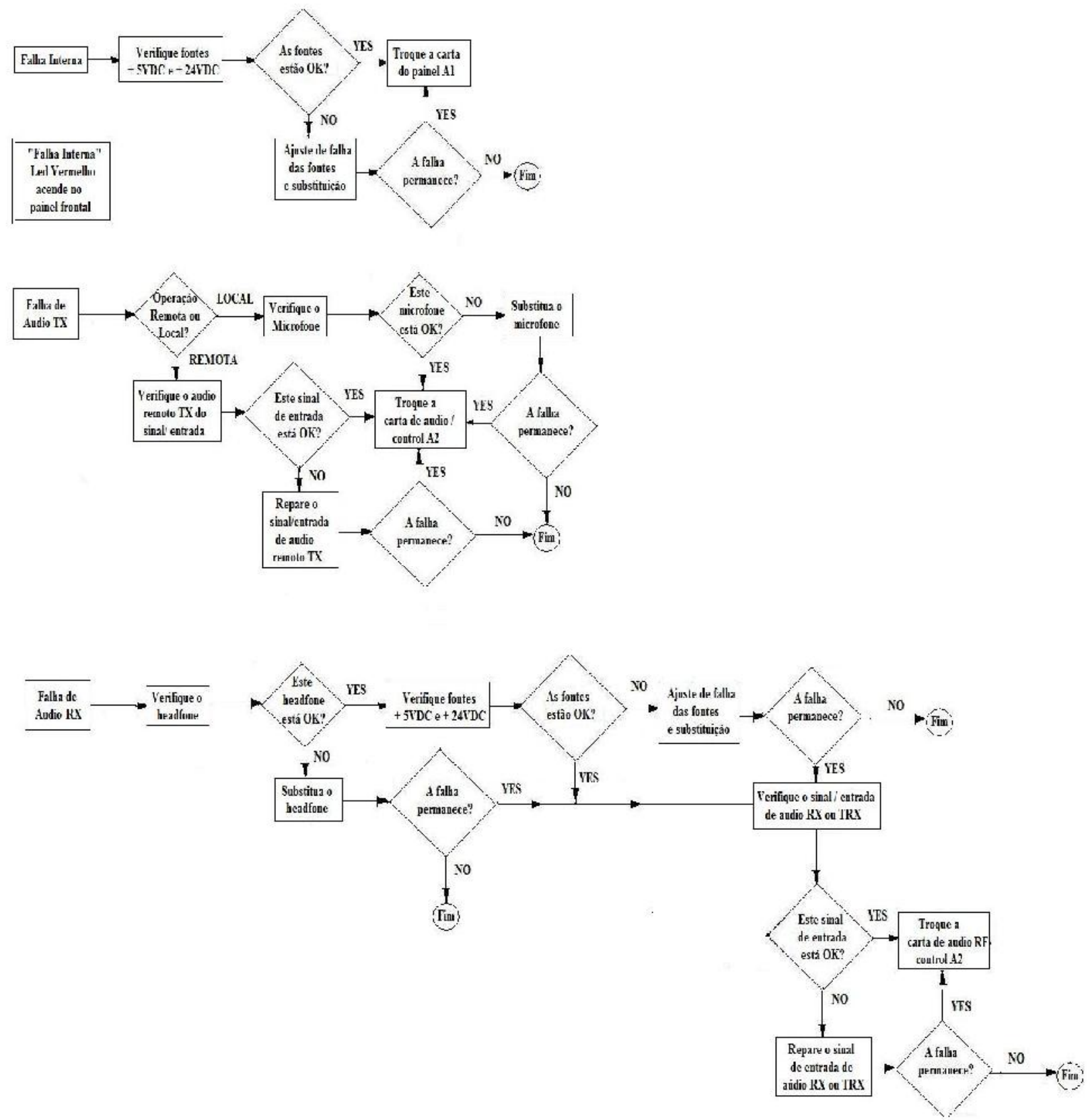

Fonte: Autoria própria (2013)

Este fluxograma é para diagnóstico de problemas no controle local relativo a falhas que possam ocorrer na fase de áudio e modulação. Um problema é a falha interna, que é visualizado quando acende no painel frontal um led da cor vermelha. O primeiro passo para solucionar a pane é verificar as fontes com o multímetro, não detectando nada o próximo passo é o ajuste das fontes, substituindo componentes, se a falha permanecer teremos que trocar a carta do painel A1. Outro problema é a falha de áudio RX. Primeiro tem que verificar o headfone com o multímetro, estando normal, o próximo passo também com o multímetro é verificar as fontes. Não detectando nada, devemos verificar o sinal de áudio com o auto falante e se o sinal esteve bom deve-se trocar a carta áudio RF control A2. 
Após a identificação e mapeamento de 4 equipamentos críticos do sistema VHF-300 do CINDACTA IV, pode-se observar 6 problemas correntes. Foram elaborados fluxogramas para cada problema, embora apresentado apenas para o VHF-350, que permitiram padronizar os procedimentos de analise e solução de falhas para os equipamentos em manutenção, atingindo assim o objetivo que é desenvolver uma rotina de diagnóstico e análise de solução de problemas para auxílio na manutenção corretiva e uma rotina de manutenção preventiva.

Esta padronização dos métodos de manutenção garante que todos os serviços serão executados segundo o mesmo critério, por qualquer executante de manutenção e em todos os equipamentos da unidade. Isso é fundamental para o gerenciamento sistêmico da manutenção.

Outro problema a ser resolvido é a alta rotatividade de militares, pois o Comando da Aeronáutica possui unidades em todos os estados brasileiros, torna-se uma cultura do militar a transferência de uma localidade para outra. No CINDACTA IV, onde o estudo foi realizado não é diferente, conforme a Quadro 3.

\begin{tabular}{|c|c|c|}
\hline \multicolumn{2}{|c|}{ Quadro 3 - Transferência de militares da seção de radio comunicação } \\
\hline Ano & Número de militares transferidos & Percentual \\
\hline 2009 & 4 & $33,3 \%$ \\
\hline 2010 & 2 & $20 \%$ \\
\hline 2011 & 1 & $10 \%$ \\
\hline 2012 & 2 & $17 \%$ \\
\hline 2013 & $3($ Dez/13) & $25 \%$ \\
\hline
\end{tabular}

Fonte: Pesquisa de campo (2013)

Como se pode observar nos últimos 5 anos houve saída de técnicos, com isso novos militares integraram a seção e sem experiência técnicas nos equipamentos. Portanto, a utilização dos serviços rotineiros, padronizados e de ampla ajuda para interação e especialização técnica. Com estes serviços rotineiros, obtidos com a padronização, melhora a confiabilidade das manutenções e a disponibilidade operativa dos equipamentos.

\section{A pesquisa de campo}

Depois de elaborado e aplicado os fluxogramas nas manutenções corretivas, foi realizado uma pesquisa de campo com os 10 militares da seção de radiocomunicação, a fim de verificar os resultados obtidos em relação aos novos procedimentos padronizados. A pesquisa da percepção qualitativa abordou o grau de satisfação dos procedimentos de manutenção de antes e depois da implantação dos métodos padronizados. O Quadro 4 apresenta o resultado da pesquisa. 
Quadro 4 - Grau de satisfação dos procedimentos de manutenção antes e depois da padronização

\begin{tabular}{|c|c|c|}
\hline Grau de Satisfação & Antes & Depois \\
\hline Ruim & 4 & 0 \\
\hline Regular & 6 & 0 \\
\hline Bom & 0 & 3 \\
\hline Ótimo & 0 & 7 \\
\hline
\end{tabular}

Fonte: Pesquisa de campo (2013)

Na pesquisa, os militares responderam se percebiam algum benefício com a padronização das atividades de manutenção corretiva. Um dado relevante é que $100 \%$ dos técnicos verificaram uma redução do tempo das manutenções, esses tempos não podem ser comparados, pois antes não havia este controle. E também foi perguntado como os técnicos executavam o serviço sem a padronização, os militares menos experientes afirmaram que sozinhos não conseguiam realizar as tarefas, mas agora com a padronização e com a ajuda dos fluxogramas já conseguiam executar os procedimentos de manutenção.

\section{Considerações finais}

Atualmente, há a necessidade de se questionar os velhos paradigmas da manutenção e da confiabilidade, que nos induzem aos mesmos erros e bloqueiam a criatividade dos atuais colaboradores, aceitando especificações e propostas de manutenção concebida pelos fabricantes, que nem sempre são profundos conhecedores da operação do seu próprio sistema. Questionar funciona como um catalisador para renovação e atualização das estratégias e táticas reinantes. Além disso, há a possibilidade de se verem confirmadas e revalidadas as práticas existentes. Com o intuito de melhorar os processos de manutenção do equipamento, através dos problemas mais comuns apresentados, podem-se sugerir ações de melhorias para manutenção corretiva.

Este trabalho teve como objetivo desenvolver uma rotina de solução de problemas de manutenção para um determinado equipamento. Os resultados mostram que é possível executar os passos do fluxograma com uma metodologia adequada e simples para a realização das atividades de manutenção. E assim, reduzir a dependência da experiência do técnico.

O planejamento da manutenção, com respeito ao mapa proposto foi de ampla ajuda na gerência e no controle dos componentes eletrônicos associados ao equipamento analisado, além da solução dos problemas mais críticos.

Por fim, podemos concluir que um sistema de manutenção padronizado dentro de uma empresa permite uma rápida e mais eficiente resposta. Sabendo que para realizar as manutenções propostas é necessário ter peças de reposição em estoque. Uma pesquisa pode ser realizada para gerenciamento, controle e supervisão da gestão de materiais aplicados às manutenções corretivas e preventivas dos equipamentos. 
Novos estudos desta mesma natureza que contemple outros equipamentos críticos podem ser desenvolvidos, visando melhorar a confiabilidade e a disponibilidade dos produtos. Entende-se que, quanto maior a quantidade de atividades científicas realizadas em um ambiente, tanto melhor para o desenvolvimento e sucesso deste recinto.

Outra pesquisa que pode ser realizada é uma análise de depreciação dos equipamentos, tendo em vista que o Comando da Aeronáutica possui muitos equipamentos que já estão sendo utilizados por diversos anos. Este estudo pode compreender indicadores de desempenho que são essenciais para revelar o tempo de manutenção do equipamento e com isso, ampliar no desenvolvimento da gestão de manutenção futuras.

Portanto, esse trabalho construiu em uma visão funcional e operacional, um mapa para as manutenções corretivas. Essa padronização dos serviços permite que os técnicos da sede ou de outras unidades realizem as mesmas atividades de manutenção, garantindo uma completa disponibilidade dos equipamentos e uma maior segurança nos voos.

\section{Abstract}

Because of the importance of aviation support equipment, it is necessary a quick replacement of a particular device. Therefore, it is imperative that a proper maintenance and technical expertise. This research presents a routine diagnostic analysis and troubleshooting for corrective maintenance equipment VHF radio system- 300, in Room Integrated Center for Air Defense and Air Traffic Control (CINDACTA IV). We also conducted a literature review focused on maintenance, standardization and consultation of technical manuals for equipment. In order to achieve the goal, the issues raised were the most common system VHF-300 in order to propose a standardization of maintenance actions. Finally, the resulted is the development of flowchart guide service technicians for routine diagnostic analysis and troubleshooting, documented procedure that did not exist before.

Key-words: maintenance; standardization; procedures.

\section{Referências}

ASSOCIAÇÃO BRASILEIRA DE NORMAS TÉCNICAS - ABNT. ISO/IEC Guide 2:2004- Normalização e atividades relacionadas - Vocabulário geral. São Paulo: 2006.

BRASIL, C. A. IMA 19-87: Metodologia para estruturação: funcionamento das manutenções de nível orgânico e de base, Brasília, DF, 1998.

BERGAMO, V. F. Confiabilidade Básica e Prática. São Paulo: E. Blucher, 1997.

CAMPOS, V. F. Gerenciamento da rotina do trabalho do dia a dia. Nova Lima: INDG Tecnologia e serviços LTDA., 2004.

CENIPA. Centro de Investigação e Prevenção de Acidentes Aeronáuticos. Brasília, 2013. Disponível em: $<$ http://www.cenipa.intraer>. Acesso em: 12 de agosto de 2013.

CINDACTA IV. Quarto Centro Integrado de Defesa Aérea e Controle de Tráfego Aéreo. Manaus, 2013. Disponível em: <http://www.cindacta4.intraer>. Acesso em: 29 de julho de 2013.

COSTA NETO, P. L. O. Qualidade e competência nas decisões. São Paulo: Edgar Blucher, 2007. 
CURI FILHO, D. Um agente de entrelaçamento. Revista Controle da Qualidade, São Paulo, v. 8, n. 80, p. 62, jan. 1999.

EDUARDO, A. C. Diagnóstico de defeitos em sistemas mecânicos rotativos através da analise de correlações e redes neurais naturais. Campinas: Unicamp, 2003.

FERREIRA, A. B. H. Novo Aurélio Século XXI: o dicionário da língua portuguesa. 3.ed. Rio de Janeiro: Nova Fronteira, 1999.

FILHO, G. B. Planejamento e controle da manutenção: Curso de Planejamento e Controle de Manutenção. 2005, ABRAMAN.

FIRMINO, P. R. A. et al. Diagramas espirais, método auxiliar para resolução ótima de árvore de falhas. In: ENCONTRO NACIONAL DE ENGENHARIA DE PRODUÇÃO, XXIV, 2004, Florianópolis. Anais... Porto Alegre, ABEPRO, 2004.

GARVIN, D. A. Gerenciando a qualidade. Rio de Janeiro: Qualitymark, 1992.

JURAN, J. M.; GRYNA, F. M. Controle da qualidade handbook: conceitos, políticas e filosofia da qualidade. São Paulo: Makron Books, 1991.

KARDEC, A. NASCIF, J. Manutenção função estratégica. 2.ed. Rio de Janeiro: Qualitymark, 2001.

LAFRAIA, J. R. B. Manual de confiabilidade, mantenabilidade e disponibilidade. Rio de Janeiro: Qualitymark, 2001.

OAKLAND, J. S. Gerenciamento da qualidade total: TQM. São Paulo: Nobel, 1994.

OLIVEIRA, M. Uma barreira para a normalização técnica. In: CONGRESSO INTERNACIONAL DE NORMALIZAÇÃO E QUALIDADE, II, 1991, São Paulo. Anais... São Paulo, ABNT, 1991.

PAYNE, N. Research to identify the types of maintenance tasks being completed from memory by B1 licensed aircraft engineers in the UK and the reasons for this memory usage. Dissertação (MSC in Human Factors and Safety Assessment in Aeronautics). Universidade de Cranfield, 2006.

PINTO, A. K.; XAVIER, J. A. N. Manutenção: função estratégica. 2a. ed. rev. amp. Rio de Janeiro: Qualitymark, 2001 .

RUDIO, F. V. Introdução ao projeto de pesquisa científica. 34 ed. Petrópolis: Vozes, 2007.

TECNASA - ELETRÔNICA PROFISSIONAL S.A. Manual técnico part number: 740-216-002-7 (VHF transmitter V310). São José dos Campos, 1993.

TECNASA - ELETRÔNICA PROFISSIONAL S.A. Manual técnico part number: 740-217-002-7 (VHF receiver V320). São José dos Campos, 1993.

TECNASA - ELETRÔNICA PROFISSIONAL S.A. Manual técnico part number: 740-214-002-9 (VHF transceiver V330). São José dos Campos, 1993.

TECNASA - ELETRÔNICA PROFISSIONAL S.A. Manual técnico part number: 740-223-001-0 (VHF Local control V350). São José dos Campos, 1993.

VERGARA, S. C. Projetos e relatórios de pesquisa em administração. 5 ed. São Paulo: Atlas, 2004.

VIANA, H. R. G. PCM planejamento e controle da manutenção. Rio de Janeiro: Qualitymark, 2002.

XENOS, H. G. Gerenciando a Manutenção Produtiva. Belo Horizonte: editora de desenvolvimento gerencia 1998. 


\section{Dados dos autores}

\section{Nome: Raphael Azevedo Rosa}

Filiação Institucional: Universidade Federal do Amazonas - Faculdade de Tecnologia

Função: Estudante finalista do curso de Engenharia da Produção

Endereço: Av. Torquato Tapajós $n^{\circ}$ 80, Vila Militar de Flores apt. 402. Flores. Manaus. CEP 69058-830

Telefone: 092-3302-3138;

e-mail: orosa_2006@yahoo.com.br

\section{Nome: Marcelo Augusto Oliveira da Justa;}

Filiação Institucional: Universidade Federal do Amazonas - Faculdade de Tecnologia;

Função: Professor Mestre do Curso de Engenharia da Produção;

Endereço: Rua 30, n 19, Quadra A-37, Conj. Jd de Versalles, Bairro Planalto, CEP 69044-770; Telefone: 092-91258387 ou 81792273 ;

e-mail: marcelo.justa@bol.com.br

Submetido em: 06/11/2013

Aceito em: 16/10/2014 